\title{
Improving flood forecasts for better flood preparedness in the UK (and beyond)
}

Article

Accepted Version

Stephens, E. and Cloke, H. (2014) Improving flood forecasts for better flood preparedness in the UK (and beyond).

Geographical Journal, 180 (4). pp. 310-316. ISSN 1475-4959 doi: https://doi.org/10.1111/geoj.12103 Available at https://centaur.reading.ac.uk/37823/

It is advisable to refer to the publisher's version if you intend to cite from the work. See Guidance on citing.

To link to this article DOI: http://dx.doi.org/10.1111/geoj.12103

Publisher: Wiley on behalf of the Royal Geographical Society

All outputs in CentAUR are protected by Intellectual Property Rights law, including copyright law. Copyright and IPR is retained by the creators or other copyright holders. Terms and conditions for use of this material are defined in the End User Agreement.

\section{www.reading.ac.uk/centaur}

\section{CentAUR}

Central Archive at the University of Reading

Reading's research outputs online 
Improving flood forecasts for better flood preparedness in the UK (and beyond)

ABSTRACT:

This winter (2013/2014) an unprecedented amount of rainfall, and coastal storms led to significant and widespread flooding across the Southern UK. We consider scientific developments in flood forecasting, organisational change in flood forecasting and how this has improved the forecasting and flood preparedness seen in this winter's flooding. We also consider the technical and communication challenges that remain in using probabilistic flood forecasts.

\section{KEYWORDS:}

UK floods, storm surge, ensemble forecasting, HEPS, Flood Forecasting Centre, 
The UK floods of Winter 2013/2014 provoked a fever of heavy criticism in public, parliament and the news media of both the government, for the reduction in flood defence spending (in real terms) (e.g. Carrington, 2014) and the Environment Agency for their long term flood management strategy and flood response (e.g. "The Environment Agency has failed us once again", Liddell Grainger, 2014). However, amid these debates and throughout the numerous flooding events there has been consistent praise for the joint Met Office / Environment Agency Flood Forecasting Centre (FFC) from the Environment Secretary Rt Hon Owen Paterson MP (HC 6 Jan 2014, Vol 573 Col 24; HC 3 Feb 2014, Vol 575 Col 24).

In this commentary we focus on the forecasting and preparedness role that the FFC fulfils as an underrepresented yet important component of our flood risk management portfolio; one that perhaps has the biggest influence on the relatively low number of deaths in the UK from floods. We consider the coming together of scientific developments in probabilistic flood forecasting and organisational change in the setup of the joint Met Office (MO)-Environment Agency (EA) Flood Forecasting Centre (FFC), and what this has meant for improvements in forecasting and preparedness in the context of this winter's events. We also consider that there is still much to do in order to further forecasts technically, and to promote the routine communication and use of probabilistic forecasts.

\section{Forecasting and Preparing for Floods}

The UK is well known for being an "epic weather theatre" (Mabey, 2013) and we should be well used to the imagery of the storms and floods that regularly appear. This winter (i.e. 2013/2014) an unprecedented amount of rainfall led to significant and widespread flooding across areas of South West and Southern England, and successive storms caused flooding from storm surges and damage from waves around the UK coastline. Flooding is a natural process that will always take place, but the likelihood of flooding is increased by paving and deforesting our catchments which then speeds up the floodwater. Communities are also made more vulnerable by building on floodplains (putting more people in harm's way). 
A holistic flood risk management approach is widely favoured by scientists and policymakers to reduce the likelihood and impact of flooding: one which approaches sustainable long term risk reduction through a combination of flood defences, water storage strategies and effective land use planning. A particularly notable response to the recent flooding is the call by local communities (and reactively by both local and national politicians) for particular immediate actions, such as the dredging of the Somerset Levels. However, any changes to flood risk management approaches are best informed reflecting on the lessons learnt from previous flood events, such as those contained within the Pitt review following the Summer 2007 UK floods (Pitt, 2008), and the Bye report following the Easter 1998 UK floods (Bye \& Horner, 1998).

In theory, the further in advance a flood event is forecast, the better our ability should be to prepare for it. At longer lead times (i.e. further in advance) the forecast may be less able to pinpoint with certainty the exact severity, timing and location of a flood, but even small probabilities can initiate valuable preparations within the flood forecasting communities themselves such as managing human resources to ensure that incident rooms are staffed, monitoring gauges more closely and stepping up modelling activities.

Emergency Responders including Police, Fire and Rescue and Local Authorities can also begin to devote resources to an imminent flood event, ensuring that their equipment is in the right places and in good working order and that enough people are on shift. The general public are not currently provided with the longer lead time forecasts that are disseminated to the emergency response community. This is due partially to the associated number of false alarms with low probability forecasts; for example, a flood forecast with a $10 \%$ probability 5 days in advance would not occur on 9 out of 10 occasions (if this probability forecast is accurate). However, more work could certainly be done to improve understanding of what could be usefully understood and acted upon at such lead times, and a collaborative learning process with local communities would perhaps enable the use of these longer lead time forecasts more widely in the future. 
The largest changes to flood forecasting practice in England, Wales and Scotland in recent years followed the Pitt Review (Pitt, 2008). Though the Summer 2007 floods were very different in character from those in 2014 , caused by intense summer rainfall rather than prolonged seasonal rainfall, the changes brought about have led to improvements in early warning that can be seen clearly in improved forecasting in 2014. In our opinion it was the superposition of two recommendations that led to the biggest change in forecasting practice: (i) the need for the $\mathrm{MO}$ and the $\mathrm{EA}$ to work together to deliver warnings and information on coming floods (ii) the desire for the provision of probabilistic warnings further in advance (at longer lead times).

The first recommendation provided an organisational and political framework for the formation of the FFC, based initially in London in 2009 and then at the MO HQ in Exeter from 2011, with a similar Scottish counterpart, the Scottish Flood Forecasting Service setup in 2011. The remit of the FFC is to provide a strategic overview of any flood risk, (fluvial, coastal, surface water and groundwater), for several days in advance (see http://www.ffc-environment-agency.metoffice.gov.uk/) in England and Wales, and it currently has the ultimate responsibility for the warning decision for surface water for Days 1 to 5 and fluvial, coastal and groundwater flooding from Days 3 to 5 . Though the FFC takes this strategic overview role, the regional EA offices maintain the responsibility of issuing flood warnings to the general public. The co-location of EA and $\mathrm{MO}$ employees enables a formal and on-the-job training programme for hydrometeorologists; building expertise in both meteorology and the workings of the $\mathrm{MO}$ and hydrology and the workings of the EA. This is a radical change in practice that required not only the necessary background science to be in place, but also to be supported by organisational and institutional ability to take on new ideas and perhaps most importantly, political will to implement.

As rainfall forecasts improve, best practice in flood forecasting is usually to undertake rainfall-runoff modelling to determine the river flow from numerical weather forecasts of rainfall for the coming few days. One of the most important developments in weather forecasting is that of 'ensemble weather predictions', 
and over the last few years the scientific development and subsequent operational implementation of a probabilistic approach to flood forecasting with the use of hydrological ensemble prediction systems (HEPS) has flourished (Cloke \& Pappenberger, 2009; Cloke et al 2009; Pappenberger et al, 2008; 2011; He et al., 2009, www.hepex.org). Interestingly these new scientific developments have emerged during the same period of time as a response was being made to the Pitt Review recommendations.

Ensemble prediction systems run a model multiple times in order to represent known errors in current observations (initial conditions) and the way that the model is setup (parameterization). In HEPS the 'ensemble' can come from an ensemble of numerical weather predictions of inland rainfall used to run a flood hydrology model to produce a probabilistic flood forecast or for the coast an ensemble of surge models (surges are a temporary lifting of the water surface through a combination of winds and low atmospheric pressure). Such an ensemble provides quantitative information on the uncertainty of the forecast by providing several possible futures and will give more reliable estimates of the probability of flooding than traditional forecasts. A recommendation for action could be triggered by either a higher probability of a lower impact flood or a low probability of a very severe flood (Dale et al, 2013). The sequence of actions typically follows the pattern (i) monitoring/forecasting, with (ii) warning dissemination running alongside (iii) event preparation (iv) on-site actions, such as barrier closure.

\section{Ensemble Flood Forecasting}

In all disciplines uptake of new science into practice is not usually straightforward, and it will depend on the difficulties of changing operational systems already in use, and the understanding of the new technology by the forecasters as well as any forecast users. The communication and understanding of hydrological ensemble predictions is also an emerging research field (Nobert et al., 2010; Demeritt et al., 2010, 2013; Pappenberger et al. 2013, Ramos et al, 2010, Stephens et al. 2012, Wetterhall et al 2013), with some of the most important barriers to their routine uptake being political and institutional (Demeritt et al, 2010). 
However, interest in the potential of ensemble forecasting for improved flood warning and preparedness in the UK was shown by a study on the benefits of ensemble flood forecasting for incident management (Environment Agency, 2012; Dale et al, 2013). Some of these developments are now in place in operational practice, with others in the pipeline for implementation in the near future.

The establishment of the FFC has proved an excellent home for fostering the development and uptake of HEPS and this can be illustrated through focussing on the use of the surge ensemble in forecasting the recent coastal flooding in early December 2014. Since December 2009 the FFC has run a hydrodynamic storm surge forecast model, driven by the MO meteorological ensemble and bathymetric data. The lead time of this ensemble was extended from 54 hours to just over 7 days in 2011 (Flowerdew et al. 2013), fortuitously in time for the winter 2013/14 storms. In addition, although the surge model runs with a 7 day lead time, a study of the ensemble meteorological models 8 days in advance gave the FFC an early indication of a potential surge, providing an early 'heads up' that there was a possibility of something happening (FFC, pers. comm).

Figure 1 shows the FFC ensemble surge forecast from the Monday before the surge ( $2^{\text {nd }}$ December). Surge elevations are shown for three locations of interest superimposed upon a graph of the tidal cycle (the water level forecast adds the forecast surge and the tidal level together), and includes the deterministic forecast (single 'traditional' model), all the ensemble members and also the ensemble mean. The figure shows that there were 2 scenarios possible for the coming Wednesday-Friday: the first and most likely scenario at this time point is with the water levels just crossing the alert thresholds, which would lead to some local flooding. However, the second and 'reasonable worst case' scenario is for a significant surge and significant flooding. Communicating forecasts where there is a low probability of a high impact event is notoriously challenging, but the FFC provided clear messaging that this significant surge scenario could not be discounted and raised awareness of this risk through the Local and National Flood Advisory Service telephone conferences, the Flood Guidance Statement and to Defra (FFC, pers.comm). 
A couple of days later, however, this worst-case scenario became the most likely scenario as confidence in the event increased. This really demonstrates the value of an ensemble prediction over a single deterministic prediction, as in this case the latter would have vastly underestimated the surge height and thus the flood risk. For this surge forecast, the FFC's use of ensemble probabilistic forecasting and a clear method of disseminating complex probabilistic information led to increased preparedness and a reduction in risk for the population affected, and we believe this is a real vindication of the importance in implementing probabilistic forecasting for better decision making and increased preparedness; as Paterson stated:

"We were organised and prepared. From the earliest signs of a possible surge threat, Government Departments and agencies, local resilience fora and local authorities were making preparations." HC Deb 10 Dec 2013, Vol 572, Col WS25

Clear benefits have been seen from earlier warning of storm surges, but the EA's river flood forecasting system currently only forecasts out to 36 hours. The FFC uses NWP data to feed a gridded hydrological model of England and Wales to produce deterministic, indicative forecasts of river levels for the next five days, and is currently looking to develop the capabilities of its ensemble river flood forecasting system in line with scheduled improvements in the resolution of the meteorological ensemble system, but further R\&D investment will be required to match the 7 day lead time of the storm surge ensemble.

The Environment Agency is also looking to use ensemble forecasting in its catchment scale flood models, but a change in forecasting practice is needed to ensure that the duty forecasters are comfortable with interpreting the probabilistic forecast. This is symptomatic of a wider challenge: ensuring that there is adequate communication and cross-learning to share local knowledges of river systems with the meteorological forecasting experience at a national scale. On a larger scale still, ensemble forecasting systems such as the European Flood Awareness System (EFAS) exist to provide longer lead time forecasts to 
complement the resources of national agencies (Thielen et al, 2009). And how far can probabilistic forecasting take us? The Global Flood Awareness System (Alfieri et al, 2013), is still in a pre-operational development stage, but working at the global scale it aims to provide provides forecasts to those nation states who do not have in-house capability and to organisations such as the World Food Programme to assist with humanitarian response.

Scientific developments have improved the spatial extent and lead times of ensemble flood forecasts, but managing these within a seamless forecasting system and a probabilistic decision-making framework remains a barrier to achieving their full potential. If this barrier can be crossed, then the world is our probabilistic oyster.

\section{Acknowledgements}

With grateful thanks to the Flood Forecasting Centre for provision of information and figures.

\section{References}

Alfieri L, Burek P, Dutra E, Krzeminski B, Muraro D, Thielen J and Pappenberger F 2013 GloFAS - global ensemble streamflow forecasting and flood early warning Hydrology and Earth System Sciences 7, 11611175, doi:10.5194/hess-17-1161-2013.

Bye P and Horner M 1998 Easter 1998 floods: Report by the independent review team to the board of the Environment Agency, Volume 1. Bristol Environment AGency 30 September.

Carrington, D (2014), Thames flood defences among schemes hit by coalition funding cuts, The Guardian $17^{\text {th }}$ February 2014, http://www.theguardian.com/environment/2014/feb/17/thames-flood-defencesfunding-cuts-heathrow-dawlish-somerset-levels

Cloke HL and Pappenberger F 2009 Ensemble flood forecasting: a review. Journal of Hydrology

Cloke HL and 25 authors 2009 Progress in the implementation of Hydrological Ensemble Prediction Systems (HEPS) in Europe for operational flood forecasting. ECMWF Newsletter No. 121 - Autumn 2009. 
Dale M, Wicks J, Mylne K, Pappenberger F, Laeger S and Taylor S 2014 Probabilistic flood forecasting and decision-making: an innovative risk-based approach, Natural Hazards, 70 (1) 159-172, 10.1007/s11069012-0483-z

Demeritt D, Nobert S, Cloke HL, Pappenberger F 2010 Challenges in communicating and using ensembles in operational flood forecasting. Meteorological Applications. 17 (2) 209-222. DOI: 10.1002/met.194

Demeritt D, Nobert S, Cloke HL and Pappenberger F 2013 The European Flood Alert System and the communication, perception, and use of ensemble predictions for operational flood risk management. Hydrological Processes 27 (1) 147-157. ISSN 0885-6087 doi: 10.1002/hyp.9419

Environment Agency 2012 Applying probabilistic flood forecasting in flood incident management, Technical Report. SC0900032. Flood and Coastal Risk Management R\&D Programme.

Flowerdew J, Mylne K, Jones C and Titley H 2013 Extending the forecast range of the UK storm surge ensemble. Q.J.R. Meteorol. Soc., 139: 184-197. doi: 10.1002/qj.1950HC Deb 10 Dec 2013, Vol 572, Col WS25 HC 6 Jan 2014, Vol 573 Col 24

HC 3 Feb 2014, Vol 575 Col 24

He Y, Wetterhall, F, Cloke HL, Pappenberger F, Wilson M, Freer J and McGregor G 2009 Tracking the uncertainty in flood alerts driven by grand ensemble weather predictions. Meteorological Applications. 16(1) Special Issue: Flood Forecasting and Warning. p 91-101

Liddel-Grainger, I, WH Deb 22 January 2014 col 124WH

Mabey R 2013 Turned out nice again: on Living with the Weather. Profile books.

Nobert S, Demeritt D, Cloke HL 2010 Informing operational flood management with ensemble predictions: lessons from Sweden. Journal of Flood Risk Management 3 72-79

Pappenberger F, Bartholmes J, Thielen J, Cloke HL, Buizza R, de Roo A 2008 New dimensions in early flood warning across the globe using grand-ensemble weather predictions. Geophysical Research Letters. 35, L10404 ISSN 1944-8007 doi: 10.1029/2008GL033837 
Pappenberger F, Thielen J. and del Medico, M 2011 The impact of weather forecast improvements on large scale hydrology: analysing a decade of forecasts of the European Flood Alert System, Hydrological Processes, 25(7), DOI : 10.1002/hyp.7772.

Pappenberger F, Stephens E, Thielen J, Salamon P, Demeritt D, van Andel S-J, Wetterhall F and Alfieri L 2013 Visualizing probabilistic flood forecast information: expert preferences and perceptions of best practice in uncertainty communication Hydrological Processes 27 (1) 132-146.

Pitt M 2008. Learning Lessons from the 2007 Floods: An Independent Review by Sir Michael Pitt. Cabinet Office: London

Ramos M-H, van Andel, S-J and Pappenberger F 2013 Do probabilistic forecasts lead to better decisions?, Hydrology and Earth System Sciences 17, 2219-2232, doi:10.5194/hess-17-2219-2013, 2013.

Stephens E, Edwards TL and Demeritt D Communicating probabilistic information from climate model ensembles-lessons from numerical weather prediction. Wiley Interdisciplinary Reviews: Climate Change 3.5 (2012): 409-426.

Thielen, J., Bartholmes, J., Ramos, M.-H., and de Roo, A. 2009 The European Flood Alert System - Part 1: Concept and development, Hydrology and Earth System Sciences, 13, 125-140, doi:10.5194/hess-13-1252009, 2009.

Wetterhall, F., Pappenberger, F., Alfieri, L., Cloke HL, Thielen-del Pozo, J., Balabanova, S., Daňhelka, J., Vogelbacher, A., Salamon, P., Carrasco, I., Cabrera-Tordera, A. J., Corzo-Toscano, M., Garcia-Padilla, M., Garcia-Sanchez, R. J., Ardilouze, C., Jurela, S., Terek, B., Csik, A., Casey, J., Stankūnavičius, G., Ceres, V., Sprokkereef, E., Stam, J., Anghel, E., Vladikovic, D., Alionte Eklund, C., Hjerdt, N., Djerv, H., Holmberg, F., Nilsson, J., Nyström, K., Sušnik, M., Hazlinger, M. and Holubecka, M. 2013 Forecasters priorities for improving probabilistic flood forecasts. Hydrology and Earth System Sciences, 17. pp. 4389-4399. ISSN 1607-7938 doi: 10.5194/hess-17-4389-2013 
Figure 1

Ensemble surge forecast for North Shields, Lowestoft and Dover from Monday 2nd

December 2013. Provided by the Flood Forecasting Centre. 